\begin{tabular}{lcl}
\hline \multicolumn{1}{c}{ PKS } & REVISTA DE GEOGRAFIA & \multicolumn{1}{c}{ OJS } \\
$\begin{array}{lcc}\text { PUBLIC } \\
\text { KNOWLEDGE }\end{array}$ & (RECIFE) & OPEN \\
PROJECT & http://www.revista.ufpe.br/revistageografia & JOURNAL \\
\hline
\end{tabular}

\title{
PERCEPÇÃO DAS COMUNIDADES LOCAIS EM RELAÇÃO AOS IMPACTOS NA SAÚDE E AMBIENTE DECORRENTES DA AMPLIAÇÃO DE UM COMPLEXO INDUSTRIAL PORTUÁRIO
}

Stevam Gabriel Alves ${ }^{1}$, Thialisson Santos Ribeiro ${ }^{2}$, Emanuelly de Arruda Marques ${ }^{3}$, Juliana Carneiro Pires ${ }^{4}$, Nathalie Alves Agripino $^{5}$, Maria José Cremilda Ferreira Alves ${ }^{6}$, Mariana Olívia Santana dos Santos ${ }^{7}$, Idê Gomes Dantas Gurgel ${ }^{8}$

\begin{abstract}
'Doutorando do Programa de Pós-Graduação em Meio Ambiente (Prodema) pela Universidade Federal de Pernambuco (UFPE). Membro do Laboratório de Saúde, Ambiente e Trabalho (Lasat)/Instituto Aggeu Magalhães/Fiocruz Pernambuco. E-mail: stevam_gabriel@hotmail.com

${ }^{2}$ Mestrando em Saúde Coletiva do Programa de Pós-Graduação em Saúde Coletiva (PPGSC) UFPE. Membro do Lasat/IAM/Fiocruz/PE. E-mail: thialisson_ribeiro@hotmail.com

${ }^{3}$ Docente do curso Gestão em Logística na Universidade de Pernambuco, Campus Palmares. Pós-graduanda no Curso de Especialização Vigilância e Promoção da Saúde, Ambiente e Trabalho pela Fundação Oswaldo Cruz Pernambuco e Brasília. Membro do Lasat/IAM/Fiocruz/PE.E-mail:manu_marques28@hotmail.com

'Pós-graduanda no Curso de Especialização Vigilância e Promoção da Saúde, Ambiente e Trabalho pela Fiocruz/PE/BSB. Bacharel em geografia. Membro do Lasat/IAM/Fiocruz/PE. E-mail: juliana_ana_nana@hotmail.com

'Pós-graduanda no Curso de Especialização Vigilância e Promoção da Saúde, Ambiente e Trabalho pela Fiocruz/PE/BSB. Bacharel em saúde coletiva (UPE). Membro do Lasat/IAM/Fiocruz/PE. E-mail: nathaliealves7@gmail.com

${ }^{6}$ Bacharel em geografia (UFPE). Graduanda em Saúde Coletiva( UFPE) Bolsista Iniciação Científica do Lasat/IAM/Fiocruz/PE. E-mail: mjcreme1991@hotmail.com

'Docente do curso de medicina Núcleo Ciências da Vida/Centro Acadêmico do Agreste/UFPE. Pesquisadora bolsista do Lasat/IAM/Fiocruz/PE.E-mail:marianaxolivia@gmail.com/mariana.ssantos@ufpe.br

${ }^{8}$ Pesquisadora do Instituto Aggeu Magalhães/Fiocruz/ PE. Integrante do Lasat/IAM/Fiocruz/PE. E-mail: ideg@cpqam.fiocruz.br
\end{abstract}

Artigo recebido em 01/05/2018 e aceito em 12/07/2018

\begin{abstract}
RESUMO
O Complexo Industrial Portuário de Suape (CIPS) em Pernambuco tem recebido grandes investimentos, tendo como finalidade a ampliação do modelo de desenvolvimento adotado pelo Estado. Com o objetivo de analisar os impactos causados pelas atividades industriais no ambiente das comunidades locais, foram realizadas: pesquisa bibliográfica e visita de campo, onde foram feitas observações e entrevistas com a população. A análise dos resultados revelou que o CIPS tem aspirado apenas o crescimento econômico e tem causado sérios danos - no ambiente e vida da população moradora do entorno. A mudança do atual modelo de desenvolvimento é fundamental. Essa transformação requer do Estado, das corporações empresariais e da sociedade civil a retomada dos direitos humanos fundamentais e a adoção de medidas de proteção ambiental, possuindo como finalidade a promoção da justiça social.
\end{abstract}

Palavras-chave: Saúde Ambiental; Vulnerabilidade Social; Conflitos Ambientais; Saúde Coletiva. 


\title{
PERCEPTION OF LOCAL COMMUNITIES IN RELATION TO HEALTH AND ENVIRONMENTAL IMPACTS RESULTING FROM THE EXPANSION OF A PORT INDUSTRIAL COMPLEX
}

\begin{abstract}
The Suape Port and Industrial Complex (CIPS) in Pernambuco has received large investments, having as its purpose the magnification of the development model adopted by the State. With the objective to analyze the impacts caused by industrial activities on the environment and the local communities, were carried out: bibliographical research and field visit, where they were made observations and interviews with the population. The analysis of the results showed that the CIPS has sucked only economic growth and has caused serious damage - on the environment and life of the population living in the vicinity. To change the current model of development is essential. This transformation requires the State, business corporations and civil society the resumption of fundamental rights and the adoption of environmental protection measures, having as its purpose the promotion of social justice.
\end{abstract}

Keywords: Environmental Health; Social Vulnerability; Environmental Conflicts; Collective Health.

\section{INTRODUÇÃO}

Atualmente no Brasil os megaempreendimentos, como os complexos industriais, as hidrelétricas e os portos, ocupam um lugar de destaque tanto nas transformações da natureza e bens comuns, quanto nos efeitos negativos gerados à saúde das populações atingidas pelas obras. A implementação dessas grandes operações estruturais está associada ao modelo desenvolvimento econômico prevalente em todo mundo (BERMANN, 2008). Pesquisas, das mais variadas fontes, indicam as contradições deste modelo de desenvolvimento, visto que diferentemente do que é posto para a sociedade, a chegada dessas empresas trouxe consigo diversas transformações e impactos na vida da população que residem circundantes ao CIPS, aos moradores que viviam ou vivem onde é hoje o Complexo Industrial, bem como nestes Territórios, como a poluição atmosférica e sonora, a modificação na qualidade da água, alterações na fauna e na flora, a violência, a perda de direitos resultantes dos conflitos entre populações locais e empreendedores, os processos de desterritorialização, além dos danos consequentes à saúde física e mental, como estresse, distúrbios nutricionais, distúrbios psicossociais, cardiopatias, doenças respiratórias e digestivas (QUEIROZ; MOTTA-VEIGA, 2012; PORTO et al., 2013; ALVES, 2016; RIGOTTO, 2008, TAMBELLINI, 2009).

Os meios pelos quais se buscam o crescimento econômico, geralmente, não são sustentáveis, e nas últimas décadas têm se exaurido e degradado os recursos naturais, além de ampliar as desigualdades sociais. Tal relação deve-se ao fato de que, até pouco tempo as questões ambientais não eram consideradas como fatores no sistema econômico e sanitário. Nesse contexto, a poluição promovida pelas indústrias não passava de mera externalidade (SILVEIRA; ARAÚJO NETO, 2014). 
Os danos causados à natureza e às populações não são ponderados pelos empreendimentos, pois os maiores objetivos eram a reprodução e acumulação de capital (FURTADO, 1974). Por isso, vários autores afirmam que estamos vivendo numa crise ambiental, que se estabeleceu como um dos maiores e mais complexos desafios da contemporaneidade (FOLADORI, 2001; LEFF, 2006; WWF, 2014). Por isso, os estudos acerca da interface entre desenvolvimento econômico, ambiente e saúde são fundamentais para o entendimento dessas complexas relações (RIGOTTO, 2008).

Em decorrência do uso exagerado dos recursos naturais pelos grandes empreendimentos, a degradação dos ecossistemas aumenta e seus efeitos incidem em maior proporção nas populações mais pobres e vulneráveis (RIGOTTO, 2002; RIGOTTO, AUGUSTO, 2007).

Esse cenário coloca o país em uma rota de insustentabilidade, fomentando a lógica da degradação ambiental mediante instalação de grandes projetos que foi marcado nos últimos anos por programas econômicos neoliberais, a exemplo do Programa de Aceleração do Crescimento (PAC) (PORTO, MILANEZ, 2009; SANTOS et al., 2016).

No período de maior investimento do PAC, Pernambuco apresentou intenso processo de reconfiguração econômica e produtiva mediante a implantação de grandes empreendimentos como o Complexo Industrial Portuário de Suape (CIPS). Localizado nos municípios de Ipojuca e Cabo de Santo Agostinho, litoral sul do estado, o CIPS teve seu funcionamento iniciado na década de 1970, mas apenas como porto. Em 1990 torna-se Complexo Industrial e Portuário devido a chegada de algumas empresas. No ano de 2005, através dos investimentos do PAC começam a ser implantadas novos processos produtivos, tendo destaque o polo petroquímico conformado pela Refinaria Abreu e Lima e a Petroquímica e um polo naval, pelos Estaleiros Promar e Atlântico Sul (SANTOS et al., 2016; SANTOS, 2017).

Esse cluster industrial proporcionou um rápido crescimento econômico, mas também reduziu as atividades de turismo e de pesca artesanal na região devido às variadas intervenções no território (construção de indústrias, dragagens do canal portuário, fechamento de cursos d'água, etc.) (MACHADO, 2014; SANTOS et al., 2016). O CIPS tem ocasionado profundas transformações políticas, econômicas, culturais, sociais, produzindo conflitos e injustiças socioambientais com repercussão danosa sobre os territórios onde vive e trabalha a população que já vivenciava situações de desigualdades sociais (ALVES, 2016; SANTOS, 2016; SANTOS, 2017). Este cenário é reflexo do modelo econômico neoliberal que produz 
impactos negativos e muitas vezes irreversíveis à natureza e que reverberam na saúde da população (TAMBELLINI, 2009) configurando-se em inúmeros processos de vulnerabilização e injustiça ambiental, conforme definição de Acselrad (2009) entende-se como:

\begin{abstract}
(...) A condição de existência coletiva própria a sociedades desiguais onde operam mecanismos sociopolíticos que destinam a maior carga dos danos ambientais do desenvolvimento a grupos sociais de trabalhadores, populações de baixa renda, segmentos raciais discriminados, parcelas marginalizadas e mais vulneráveis da Cidadania (ACSELRAD, 2009, p. 16).
\end{abstract}

Os conflitos socioambientais têm sua origem na luta contra a reprodução das desigualdades sociais e têm distintas formas de se manifestarem, podendo resultar tanto do inconformismo de populações com a instalação de indústrias poluentes em proximidade às suas moradias, quanto à luta pelo acesso a recursos naturais necessários à sua reprodução. Os conflitos são materializados a partir do momento que se questiona o modelo de desenvolvimento, seus impactos e o comprometimento aos recursos naturais (PORTO et al., 2013).

Nesse sentido, a relação entre o desenvolvimento econômico em consonância com o binômio saúde-natureza é uma agenda em destaque no debate contemporâneo que permeia a questão dos megaprojetos e seus impactos nos ecossistemas incluindo as populações. Ao destacar este debate, o objetivo do artigo é analisar a percepção dos moradores das comunidades locais em relação aos impactos no ambiente e na saúde causados pelas recentes atividades industriais no CIPS.

\title{
MÉTODO
}

Trata-se de uma pesquisa qualitativa de caráter exploratório para análise da percepção dos moradores locais acerca das injustiças e conflitos socioambientais vivenciados.

O território de estudo foi o Engenho Mercês, comunidade reconhecida como quilombola em 2017 e que teve parte de seus moradores desterritorializados para instalação da Refinaria Abreu e Lima. A comunidade está localizada na Zona Industrial Portuária do CIPS, no município de Ipojuca/Pernambuco, por onde transpassam as principais vias de acesso à área do porto. Os grandes empreendimentos como a Refinaria Abreu e Lima, M\&GPolímeros, Petroquisa estão situados nas terras desse antigo engenho, de onde nasce o Rio Tatuoca, cujas 
nascentes localizam-se na área de instalação da Refinaria (ALVES, 2014). Esta comunidade foi formada por ex-escravos pertencentes à Usina Salgado, que era proprietária de 18 engenhos, inclusive o Engenho Mercês. Atualmente esta comunidade possui cerca de 480 famílias que vivem da pesca, coleta de caranguejo, mariscos e colheita de frutas.

Foram realizadas pesquisa bibliográfica sobre tema e visitas exploratórias para observação direta da relação das comunidades locais com o território e os impactos em relação ao ambiente, vida e trabalho desse grupo. Para coleta de dados foram utilizados registros de diário de campo, registro fotográfico e entrevistas semiestruturadas.

O roteiro para entrevista foi estruturado com 19 perguntas relacionadas à interferência da refinaria na comunidade, contaminação ambiental, saúde, utilização de recursos naturais, assistência social pela empresa Suape e realocação. Ao todo foram realizadas 25 entrevistas, todas gravadas e autorizadas através do Termo de Consentimento Livre e Esclarecido (TCLE). Os nomes dos participantes foram mantidos em sigilo, para garantir e preservar suas identidades sociais. A coleta de dados foi realizada em dois períodos, sendo o primeiro no mês de novembro de 2014 e o segundo entre julho e setembro de 2015. Os critérios de inclusão dos entrevistados foram: maior de 18 anos; morador nativo da região; residir na comunidade Engenho Mercês há mais de 10 anos e proximidade da refinaria. A pesquisa foi aprovada pelo comitê de ética do Instituto Aggeu Magalhães/Fiocruz-PE, sob o registro CAEE de número: 44507115.5.0000.5190.

A técnica metodológica empregada para análise dos dados, perpassou a primeira fase da análise de conteúdo, ou seja, a pré-análise, cujas leituras flutuantes permitiram a fragmentação em frases emergentes das entrevistas transcritas. Para Bardin (2011), a técnica de análise de conteúdo consiste na categorização de mensagens em unidades temáticas de forma sistemática, com descrição objetiva, que permitam inferir sobre os conhecimentos no sentido de buscar o que se esconde sob a aparente realidade.

\section{RESULTADOS E DISCUSSÃO}

\section{Mudanças territoriais, conflitos e injustiças socioambientais}

Comumente os megaempreendimentos são apresentados a população pelos representantes Estatais, empresariais e meios de comunicação de grande circulação como indispensáveis ao desenvolvimento regional, mas estudos do campo da ecologia política, 
saúde ambiental e saúde do trabalhador apontam que na verdade eles beneficiam apenas uma parcela da sociedade (SANTOS, 2017). Dessa forma, nada acrescentam para as populações atingidas, ao contrário, expulsam-nas de seus territórios, impedindo de reproduzir seus meios de produção, sua cultura e as relações sociais (GIONGO et al., 2015). Outro ponto que merece ser ponderado é que esses megaprojetos raramente agregam em suas despesas os custos de exploração e degradação dos recursos naturais, retomando o pensamento do século passado, no qual os recursos naturais eram considerados como fonte de matéria prima inesgotável (HAUGHTON, 2004).

As injustiças ambientais no CIPS surgem por meio de interesses e objetivos distintos que cruzam o mesmo espaço. O primeiro ponto está relacionado ao porto como espaço econômico, orientado para o negócio, no qual, o moderno se sobrepõe ao tradicional, e o segundo são as comunidades que primam por seu bem-estar e qualidade de vida, que estão ali localizadas há dezenas de anos.

Dentre os variados empreendimentos presentes no polo industrial de Suape, em especial a Refinaria, a Petroquímica, Termelétrica e os Estaleiros, nota-se um grande desrespeito às leis ambientais atuais, a falta de responsabilidade socioambiental das empresas que se instalaram e, principalmente, a invisibilidade aos olhos dos órgãos ambientais estaduais à degradação ambiental (COSTA, 2014). Os efeitos dessa política que considera a natureza e as populações tradicionais - pescadores, mariqueiras, quilombolas - como um obstáculo ao crescimento econômico, tem como resultado a interrupção drástica dos modos de vida da população local, ferindo direitos humanos fundamentais.

O discurso dos entrevistados sobre a compreensão relacionada às mudanças no território e as suas consequências, decorrentes das obras de implantação e expansão da Refinaria Abreu e Lima reúne e denuncia um conjunto variado de injustiças ambientais por vezes, irreversíveis:

Entrevistado 18. "Mudou muito, visse! Antes tinha mais frutas, mais caranguejo. Hoje tudo isso tá diminuindo. O desmatamento tá acabando com tudo”.

Entrevistado 11. "Piorou tudo, porque os povo não tem mais emprego. Pra quem é daqui não dão, só pra quem é de fora. Aqui não tem ninguém empregado”.

As famílias têm como principal atividade a pesca artesanal, porém os danos profundos aos bens comuns (água, terra, vegetação) tem levado o desaparecimento das espécies, obrigando-os a buscar outras formas de sobrevivência, inclusive na construção das indústrias que estão destruindo seus territórios, entretanto não são todos que conseguem emprego. Os 
moradores do Engenho Mercês vêm sofrendo com os danos ambientais e a expropriação de seus territórios desde a década de 1990 com o processo de modernização do porto de Suape e a partir do ano de 2000, até os dias atuais, as remoções são retomadas com a ampliação do parque industrial (PÉREZ; GONÇALVES, 2012).

As obras de estruturação de cada indústria - construção de canais, estradas, pontes, dragagens - multiplicam ainda mais os problemas socioambientais no território. Por exemplo, com a construção de uma ponte para o acesso de transporte terrestre ao estaleiro Atlântico Sul, o fluxo das águas marinhas foi alterado e é uma das causas da morte do mangue. Nas visitas à comunidade foi possível observar vários danos ao ecossistema, como peixes mortos e caranguejos lutando para sobreviver nas novas condições do manguezal.

No que diz respeito ao local de implantação desse empreendimento, observam-se dois pontos que se contrapõem, o primeiro está ligado ao discurso "desenvolvimentista" que tem o foco apenas na economia e veiculado frequentemente na mídia, e o outro traz em seu bojo as verdades ocultas que levaram à implantação da refinaria em Suape, como veremos adiante.

Do ponto de vista econômico, os principais fatores que determinaram a localização da refinaria em Pernambuco foram a forte vocação industrial e portuária, a infraestrutura e a facilidade de escoamento da produção. A expectativa é de significativa contribuição na expansão do Produto Interno Bruto (PIB) pernambucano ao iniciar suas atividades, fortalecendo atividades tradicionais, bem como o surgimento de novas atividades de alto dinamismo, além de um aumento na arrecadação tributária pernambucana (AGÊNCIA ESTADUAL DE PLANEJAMENTO E PESQUISAS DE PERNAMBUCO, 2005).

Os relatos de Gurgel et al. (2010) revelam um propósito que vai além dos discursos políticos e econômicos que orientaram a instalação da refinaria em Suape. Para os autores, a opção desse território foi devido ao fato da área fornecer maiores taxas de lucro e menores resistências sociais e políticas voltadas ao controle da poluição e das injustiças sociais do que outras regiões, prática esta conhecida como chantagem locacional.

O ônus do tão almejado progresso recaiu sobre as populações mais vulneráveis. Nesse sentido, Oliveira (1999) relatou uma série de impactos negativos associados às atividades portuárias que atingiu e ainda atingem diretamente as populações sobrepostas por esses empreendimentos, que vão desde a implantação até a fase de operação, ocasionando: degradação de ecossistemas, de recursos pesqueiros, da paisagem, da região e alteração da qualidade do ambiente; poluição atmosférica devido às atividades geradoras de poeira e 
emissão de poluentes resultantes da queima de combustíveis; degradação de mananciais devido aos vazamentos e lançamentos de efluentes industriais; impactos relacionados à supressão de vegetação que altera a fauna e flora; efeitos sobre a saúde da população, relacionadas às doenças infectocontagiosas, devido à presença de pessoas de diferentes regiões na área portuária, assim como em função da degradação da qualidade da natureza do entorno.

É notável que a localização de grandes projetos de transformação socioambiental requeridos pelos processos de desenvolvimento, prioriza áreas ocupadas por grupos de baixa renda ou populações tradicionais por serem enfraquecidas politicamente, sendo assim, mais fáceis de manejar (ACSELRAD, 2010). Assim foi possível observar nos territórios ocupados pelo CIPS, onde as injustiças vêm sendo ocultadas pelos interesses econômicos dos setores empresariais e governamentais, principalmente, nos veículos midiáticos que suprimem os efeitos negativos desse modelo e ressaltam a geração de emprego e benefícios econômicos como ganho social (SANTOS, 2013).

As desigualdades ambientais, associadas às pressões de mercantilização advindos dos processos econômicos privados, por meio de vários mecanismos se apropriam das várias formas do direito à terra e os transformam em direitos exclusivos da propriedade privada, retiram das populações tradicionais a possibilidade de usufruir de seu território, a exemplo da pescaria, ilustrada pela figura 1, a qual é praticada pelos moradores da comunidade como meio de subsistência. Dessa forma, promovendo a mercantilização da força de trabalho dessas populações, visto que não terão outra atividade laboral a não ser nos empreendimentos privados (ACSELRAD et al.,2012).

Assim, os processos de produção e reprodução do modelo econômico dominante, favorecem o surgimento de injustiças e conflitos sociais, uma vez que, "inviabilizam a existência de diversos grupos cuja reprodução social depende das suas relações com o território, com a diversidade biológica e geofisiográfica" (ACSELRAD et.al., 2012, p. 169). 
Figura 1: Morador se preparando para pescaria nos arredores da comunidade. Engenho Mercês, Suape, Pernambuco, Brasil.

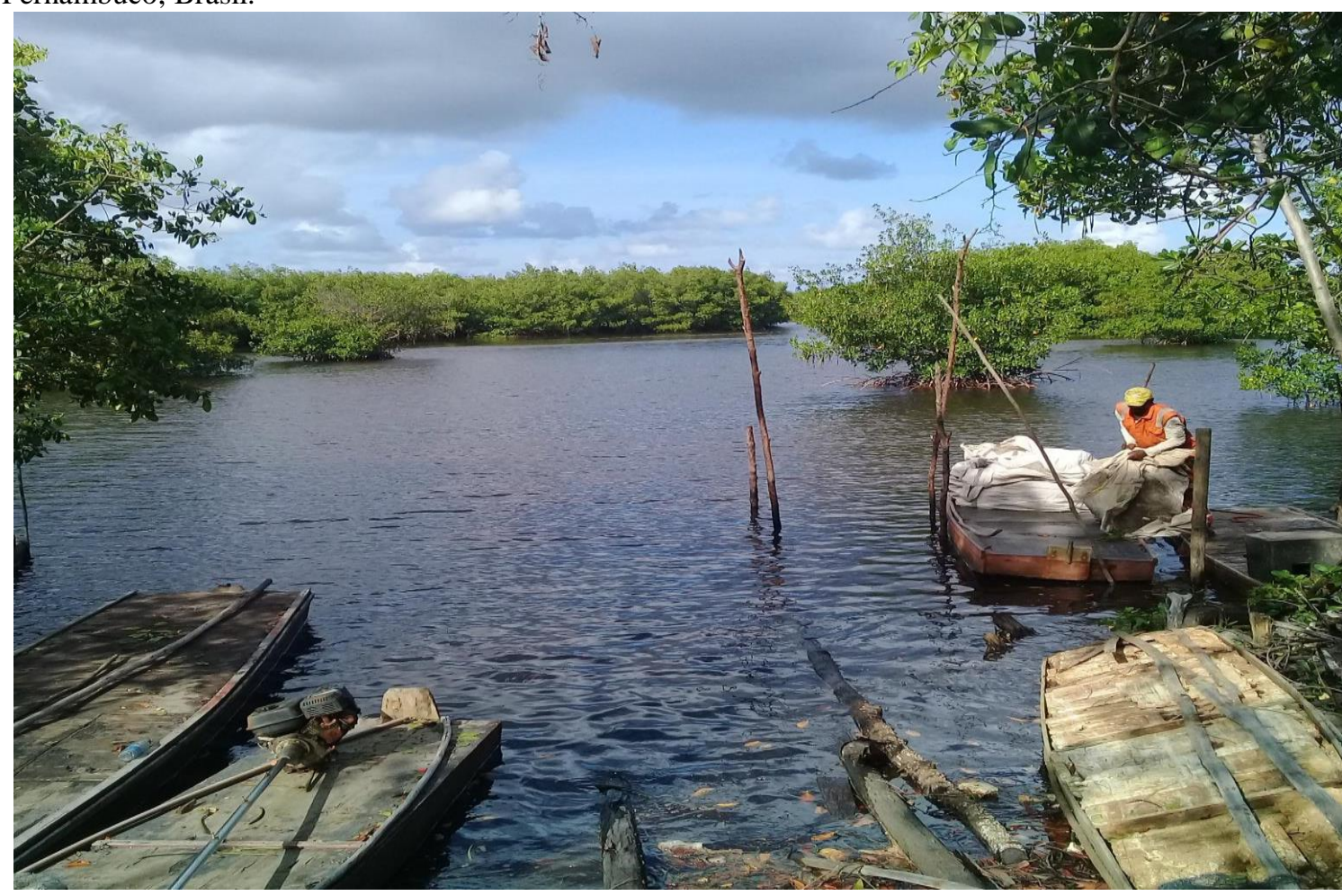

Fonte: Acervo da pesquisa, 2018

Reflexos das obras da Refinaria de Petróleo Abreu e Lima nos territórios de vida

As atividades das refinarias apresentam um dos mais altos níveis de mudanças relacionadas ao trabalho e ao trabalhador, ao ambiente e ao território apropriado. A Refinaria Abreu e Lima foi construída dentro da região portuária de Suape e para sua implantação houve a supressão de uma área de manguezal com cerca de 650 hectares, foram construídas pontes e mudanças nos fluxos das águas do mar, o que tem causado a morte desse ecossistema (Figura 2), além de estarem localizadas ao lado de comunidades que já habitavam essas terras antes mesmo do surgimento do Porto de Suape na década de 1970, e desde sua fase de implantação, as atividades dessa indústria vêm alterando a dinâmica de vida dessas populações (ALVES, 2016). 
Figura 2: Interferência no Ecossistema local pela construção de uma ponte para acesso às indústrias. Distrito Industrial Portuário de Suape, Ipojuca - PE.

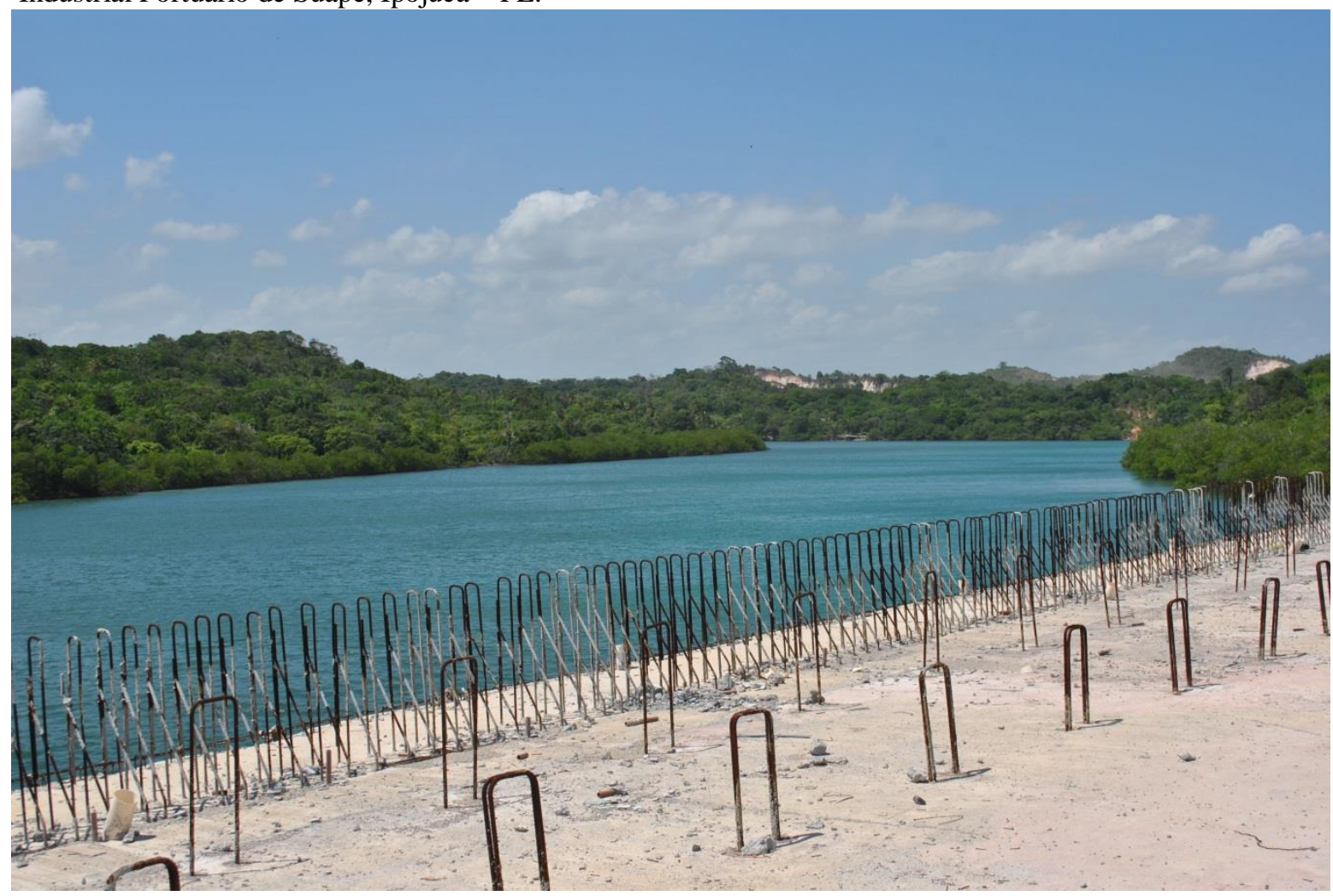

Fonte: Acervo da pesquisa, 2016.

Uma das grandes expectativas da população com a chegada dessa indústria foi a abertura de novos empregos, no entanto, esses empregos possuem contratos precários sem direitos trabalhistas assegurados, baixos salários e péssimas condições de trabalho, além de serem provisórios - duram até o final da fase de construção do empreendimento, visto que para sua operação, são contratadas apenas mão de obra altamente qualificada. O resultado desse processo foi uma onda de demissão em massa na medida que as obras são finalizadas. Os relatos dos povos tradicionais corroboram essa afirmativa:

Entrevistado 5. "O desemprego tá demais! Tem gente passando fome, o governo não vê isso. Não pego um caranguejo, não dá pra sobreviver, você sabe”.

Entrevistado 16. "Tem muito desemprego, meu marido vive do mangue e da pesca, só sobrevivo com isso".

Entrevistado 1. "Pra mim ficou pior, nunca precisei delas pra nada (empresas), nunca trabalhei nelas e acabou com minha convivência, porque não tinha intenção em sair daqui, e agora com essa indústria aí a gente não tem mais condição".

Aqui, torna-se evidente que esse modelo de desenvolvimento, representado no território pela refinaria, é altamente prejudicial, principalmente, para os moradores das comunidades do seu entorno. Os impactos gerados por esse empreendimento não são os 
únicos problemas aos moradores, visto que as atividades desta cadeia produtiva têm influenciado na modificação de sua saúde. Segundo Rigotto (2008), isso se dá, através de diversas mediações: históricas, políticas, econômicas, sociais e culturais. São forças que se articulam para produzir, sustentar e reproduzir a ideologia do desenvolvimento, tendo a ocultação dos impactos negativos, tais como (sofrimento, dor, adoecimento e poluição) como fator imprescindível.

Entrevistado 3. "Tinha uma água com o cheiro muito forte, os peixes da lagoa morreu tudo por causa dessa água ai. Esse cheiro de gás estava incomodando muito, dava dor de cabeça”.

Entrevistado 5. "A refinaria tem afetado na saúde da minha familia, dor de cabeça pela zuada e pelo gás afetou a saúde do meu filho”.

Entrevistado 2. "O ruim é o cheiro que a gente sente e às vezes fica mais forte à noite e a zuada da chama ali fica muito barulho também. A porta fica vibrando e o gás chega pra cá”.

Em todas as fases do processo produtivo do refino há potencial para causar impactos sobre o ambiente e a saúde das populações em função dos efeitos dos produtos tóxicos. Sabese que os hidrocarbonetos aromáticos presentes no petróleo, tais como o benzeno, tolueno e xileno (BTX) têm efeitos mutagênicos, carcinogênicos, teratogênicos, neurotóxicos e apresentam tóxico agudo, sendo mielotóxicos (GURGEL et al., 2009).

A exposição humana pode ser ocupacional ou ambiental, na presente pesquisa foi possível verificar algumas formas de contaminação ambiental que ocorre quando esses compostos são liberados mediante a efluentes industriais, vazamentos, emissões fugitivas ou deposição inadequada de resíduos nas águas, terra e ar.

Outros problemas danosos à saúde referem-se à poluição sonora, podendo ocasionar perda gradativa da audição e interferência no sistema nervo; às emissões atmosféricas de monóxido de carbono, podendo levar a dor de cabeça, irritação no olhos, asfixia, hipóxia e tontura; aos problemas relacionados a resíduos sólidos que favorecem o aumento da morbimortalidade por doenças infecciosas e parasitárias, dentre outros (GURGEL et al., 2009).

É habitual que megaprojetos públicos ou privados deixem de contabilizar os custos dos danos à saúde das pessoas e os prejuízos ao ambiente. Sem essa estimativa, são as populações mais enfraquecidas que pagam pelos prejuízos, enquanto uma pequena parcela da sociedade usufrui dos benefícios da obra (SILVEIRA; ARAÚJO NETO, 2014).

Com a chegada das indústrias em Suape, em específico, a Refinaria Abreu e Lima (figura 3 ilustrando a construção da refinaria), surge a poluição hídrica, sonora e atmosférica 
por meio de suas atividades produtivas, modificando a qualidade de vida das populações e causando o adoecimento das mesmas. Quando o petróleo chega à refinaria, inicia-se a etapa de refino, que se caracteriza por elevados riscos à saúde humana e de agressão à natureza em razão da emissão de poluentes provenientes do fracionamento do petróleo. O referido processo é o mais intenso na utilização de dois insumos indispensáveis para a humanidade: água e energia. A água utilizada que é descartada contém substâncias químicas, além de outras matérias orgânicas e metais. O tratamento que é realizado não consegue eliminar totalmente estes resíduos, e contaminam os cursos d'água. Junto a isso, as refinarias são indústrias propensas a grandes desastres, como explosões e vazamentos, além dos rotineiros vazamentos em pequena escala como grandes acidentes (COSTA, 2014).

Aliado a esse fato, nas atividades de fracionamento do petróleo surgem outros dois problemas. Um é referente à queima de combustíveis fósseis (figura 4), responsável pela difusão de poluentes atmosféricos como carbono e enxofre, modificando a qualidade do ar (COSTA, 2014). O outro diz respeito à poluição sonora, relacionados aos ruídos gerados nessa atividade produtiva através da queima de frações gasosas do petróleo nas torres de fracionamento.

Figura 3: Queima de combustíveis fósseis no entorno da comunidade de Engenho Mercês, Suape, Pernambuco, Brasil.

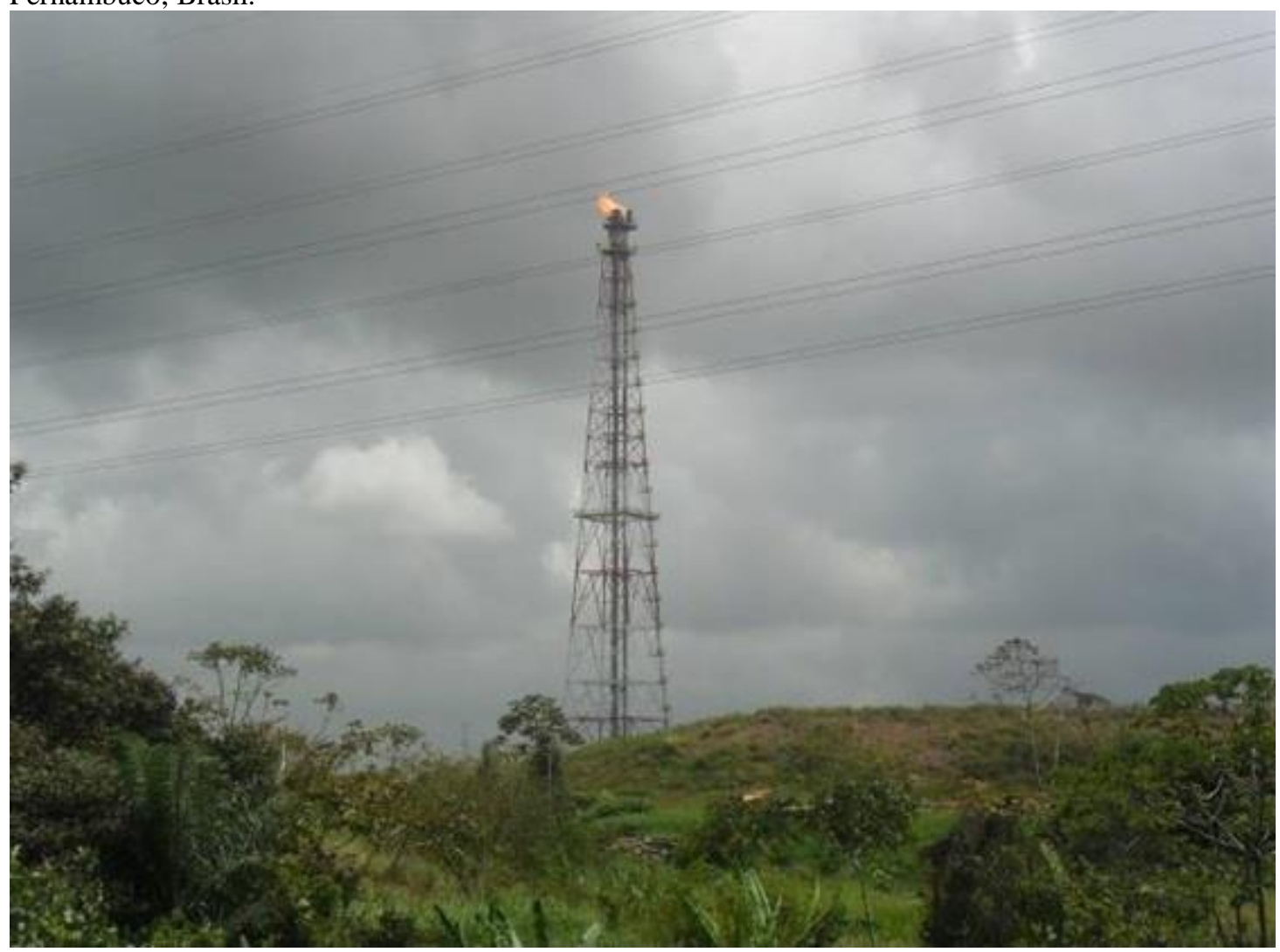

Fonte: Acervo da pesquisa, 2016. 
Dessa forma, é possível verificar que esta cadeia produtiva tem interferido no território, impactando negativamente na qualidade de vida das populações que vivem no entorno deste empreendimento. A esse respeito, alguns moradores se pronunciaram em questão:

Entrevistado 2. "Tinha uma água com o cheiro muito forte, os peixes da lagoa morreu tudo por causa dessa água aí, e esse cheiro de gás tava incomodando muito que dava dor de cabeça" (figura 5).

Entrevista 6. "De noite é um barulho enorme, a pessoa se acorda doidinha, parece que o mundo tá se acabando e às vezes tem um gás, quando o vento tá pra cá, e tudo vem de lá" (refinaria).

Figura 4: Duto de drenagem dos efluentes da Refinaria Abreu e Lima no entorno da comunidade de Engenho Mercês, Suape, Pernambuco, Brasil.

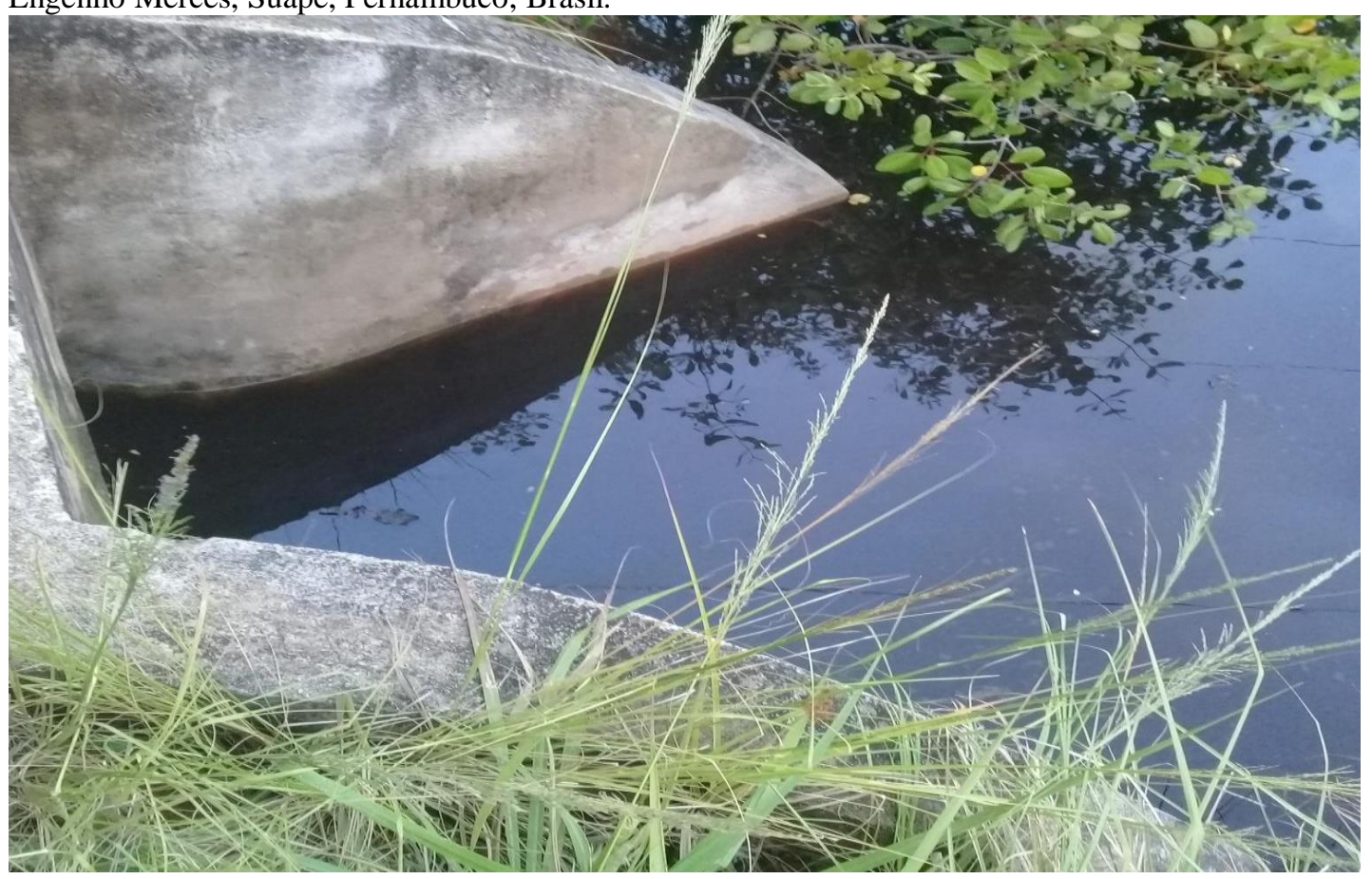

Fonte: Acervo da pesquisa, 2016

Nesta perspectiva, a saúde das populações e a exposição a diferentes situações de risco precisam ser compreendidas no interior de disputas políticas e simbólicas envolvendo os distintos projetos e usos dos recursos nos territórios, assim como o uso do poder para impor tais projetos. Para além da utilização da força direta, o poder se expressa por meios econômicos, políticos e simbólicos em diferentes instâncias (PORTO e PACHECO, 2009).

Portanto, fica evidente que a população residente ao lado desse grande empreendimento tem demonstrado através de suas falas, que vem sofrendo injustiças ambientais ocasionadas pelos processos produtivos do CIPS, em especial pela Refinaria 
Abreu e Lima, sendo necessário um processo de reparação desses danos através do Governo, que é responsável pela saúde e bem estar da população (Art. 196 e 193/CF, 1988), também na fiscalização dos projetos e possíveis impactos das instalações destas empresas, através da atuação de órgãos públicos incumbidos neste trabalho permitindo que o cumprimento dos direitos positivados na Constituição Federal e por meio de leis seja cumprida pela classe mais privilegiada, não somente a cargo da classe subalterna.

\section{CONCLUSÃO}

Este estudo identifica que as atividades produtivas do CIPS, a exemplo da Refinaria Abreu e Lima são os responsáveis pelos processos de injustiças socioambientais que atingem as populações moradoras do território, emergido, principalmente, através dos danos relacionados ao trabalho, à saúde e à natureza.

Para reverter esse cenário é fundamental a mudança do modelo de desenvolvimento hegemônico atual, caracterizado, dentre tantos outros, por processos produtivos que degradam o meio ambiente e comprometem a vida e a saúde das populações, a exemplo, a Refinaria de Petróleo Abreu e Lima, que requer do Estado, das corporações empresariais e da sociedade civil, a retomada dos direitos humanos fundamentais e a adoção de medidas de proteção ambiental, visando à promoção da saúde e a justiça social.

\section{AGRADECIMENTOS}

Este artigo integra o Projeto de pesquisa "Vulnerabilidade socioambiental relacionada à exposição química nos territórios de desenvolvimento das cadeias produtivas de petróleo e das consumidoras de agrotóxicos", financiado pelo Conselho Nacional de Desenvolvimento Científico e Tecnológico (CNPq), processo 481754/2013-0 e pela Fundação de Amparo à Ciência e Tecnologia de PE (Facepe), através do edital Apoio ao programa de excelência em pesquisa (Proep), processo APQ-1598-4.06/15. 


\section{REFERÊNCIAS}

ACSELRAD, Henri. Mediação e Negociação de Conflitos Socioambientais. IX encontro temático da $4^{\circ}$. Câmara da Coordenação e Revisão do Ministério Público Federal. Brasília, 2010.

ACSELRAD, H.; ALMEIDA, A. W. de; BERMANN, C.; BRANDÃO, C. A.; CARNEIRO, E.; LEROY, J. P.; RIGOTTO, R.; ZHOURI, A. Desigualdade Ambiental e Acumulação por Espoliação: o que está em jogo na questão ambiental? Rio de Janeiro. 2012.

. O que justiça ambiental? Rio de Janeiro: Garamond, 2009.

AGÊNCIA ESTADUAL DE PLANEJAMENTO E PESQUISAS DE PERNAMBUCO. Estudos dos impactos dos investimentos na economia pernambucana: Unidades da BR FOODS, HEMOBRÁS, Estaleiro Atlântico Sul, Petroquímica Suape e Refinaria Abreu e Lima: uma visão a partir da Matriz Insumo-Produto de Pernambuco, 2005. Disponível em:<http://www.portais.pe.gov.br/c/document_library/get_file?uuid=bd676e1a-8bdd-496f8eb0-b32019d6b4d7\&groupId=19941>. Acesso em: 02/06/2017.

ALVES, S. G. Injustiças Socioambientais e Interferências na Saúde de Populações Localizadas na Área do Complexo Industrial Portuário de Suape. Dissertação (Mestrado), Programa de Pós-Graduação em Desenvolvimento e Meio Ambiente, UFPE. Recife, 2016.

Bardin, L.(2011). Análise de conteúdo. São Paulo: Edições 70.

BERMANN, C. Crise ambiental e as energias renováveis. Ciência e Cultura, Campinas, v. 60, n. 3, p. 20-29, 2008.

BRASIL. [Constituição (1988)]. Constituição da República Federativa do Brasil [recurso eletrônico]. -- Brasília: Supremo Tribunal Federal, Secretaria de Documentação, 2018. 518 p. Atualizada até a EC n. 99/2017.

BULLARD, Robert. Enfrentando o racismo ambiental no século XXI. In: ACSELRAD, Henri; HERCULANO, Selene; PÁDUA, José Augusto (Org.). Justiça ambiental e cidadania. Rio de Janeiro: Relume Dumará, 2004.

CAVALCANTI, C. Desenvolvimento e Meio Ambiente: O Conflito do Complexo IndustrialPortuário de Suape, Pernambuco. In: IV Encontro Nacional da Anppas, Brasília, Jun. 2008. 
COSTA, H.S.. Suape: Promessas não Cumpridas (2). In: Correio da Cidadania. 2014b.Disponível

em:

$<$ http://www.correiocidadania.com.br/index.php?option=com_content\&task=view\&id=9743

\&Itemid=79>. Acesso em:08/08/2015.

DUARTE, R. Entrevistas em pesquisas qualitativas. Educar, Curitiba, n. 24, p. 213-225, 2004. Editora UFPR.

FOLADORI, Guillermo. Limites do desenvolvimento sustentável. Campinas, SP: Editora da Unicamp, 2001.

FURTADO, C. O mito do desenvolvimento econômico. Rio de Janeiro: Paz e Terra, 1974.

GIL, A. C. Como elaborar projetos de pesquisa. 4. ed. - São Paulo : Atlas, 2002.

GIONGO, C. R.; MENDES, J. M. R.; SANTOS, F. K. Desenvolvimento, saúde e meio ambiente: contradições na construção de hidrelétricas. Serv. Soc. Soc., São Paulo, n. 123, p. 501-522, jul./set. 2015.

GURGEL, I. G. D.; AUGUSTO, L. G. S.; GURGEL, A. M.; SILVA, J. M.; SANTOS, M. O. S. O impacto da cadeia de petróleo de Suape na Saúde do Trabalhador. Revista Coletiva, v. 02, p. 01-06, 2010.

GURGEL, A. M.; MEDEIROS, A. C. L. V.; ALVES, P. C.; SILVA, J. M. da; GURGEL, I. G. D.; AUGuSto, L. G. da S. Framework dos Cenários de Risco no Contexto da Implantação de uma Refinaria de Petróleo em Pernambuco. Ciência \& Saúde Coletiva, 14(6):2027-2038, 2009.

HAUGHTON, G. Urban growth and the urban environment. In: HAUGHTON, G.; HUNTER, C. Sustainable cities: regional development and public policy. London: Routledge, 2004.

LEFF, E. Racionalidade Ambiental: a reapropriação social da natureza. Rio de Janeiro: Civilização Brasileira, 2006.

MACHADO, M. R. I. DE M. O Complexo Portuário de Suape e as novas dinâmicas sócioterritoriais nos municípios do Cabo de Santo Agostinho e Ipojuca: o início do desmonte do território canavieiro na Zona da Mata pernambucana? Vitória/ES, 2014. 
MINAYO, M. C. de S. Ciência, técnica e arte: o desafio da pesquisa social. In: (Org.). Pesquisa social: teoria, método e criatividade. Petrópolis, RJ: Vozes, 2001.

OLIVEIRA. M. do C. D. de. Manual de impactos ambientais: orientações básicas sobre aspectos ambientais de atividades produtivas. Banco do Nordeste: Fortaleza, 1999.

PÉREZ, M. S.; GONÇALVES, C. U. Desenvolvimento e Conflito Territorial: primeiras reflexões sobre as comunidades atingidas pelo complexo industrial portuário de Suape -PE, Brasil. Revista de Geografia, v. 29, n. 2, p. 167-179. Recife, 2012.

PORTO; M F.; PACHECO, T.; LEROY, J. P. Injustiça Ambiental e Saúde no Brasil: o mapa de conflitos. Rio de Janeiro: Fiocruz; 2013.

PORTO; M F.; PACHECO, T. Conflitos e injustiça ambiental em saúde no Brasil. Tempus. Actas em Saúde Coletiva, vol. 4, n. 4, p. 26-37. 2009

PORTO, M. F.; MILANEZ, B. Eixos de desenvolvimento econômico e geração de conflitos socioambientais no Brasil: desafios para a sustentabilidade e a justiça ambiental. Ciência \& Saúde Coletiva, Rio de Janeiro, 2009, v. 14, n. 6, p. 1983-1994, 2009.

QUEIROZ, A. R. S. de; MOTTA-VEIGA, M. Análise dos impactos sociais e à saúde de grandes empreendimentos hidrelétricos: lições para uma gestão energética sustentável. Ciência \& Saúde Coletiva, Rio de Janeiro, v. 17, n. 6, p. 1387-1398, 2012.

REDE BRASILEIRA DE JUSTIÇA AMBIENTAL. Crise conjuntural e expropriação permanente: petróleo e injustiças ambientais no Brasil. 2015. Disponível em: <http://racismoambiental.net.br/2015/05/06/crise-conjuntural-eexpropriacaopermanentepetroleo-e-injusticas-ambientais-no-brasil/>. Acesso em 11/06/2015.

RIGOTTO, R. M. Democratizou-se a poluição?: Um estudo dos riscos tecnológicos e ambientais associados à industrialização em região semi-árida do Brasil. Scripta Nova Revista electrónica de geografía y ciencias sociales, Barcelona, Espanha, v. VI, n. 111, 2002.

RIGOTTO, R. M. Desenvolvimento, ambiente e saúde: implicações da (des)localização industrial. Rio de Janeiro: Fiocruz, 2008.

RIGOTTO, R. M.; AUGUSTO, L. G. S. Saúde e ambiente no Brasil: desenvolvimento, território e iniqüidade social. Cadernos de Saúde Pública, Rio de Janeiro, v. 23, n. supl. 4, p. S475-S485, 2007. 
SANTOS, M. O. S.; ALVES, S. G.; SILVA, J. M. ; MERTENS, F. ; GURGEL, I. G. D.; AUGUSTO, L. G. S. . Excluídas pelo Desenvolvimento: Mulheres e o Complexo Industrial Portuário de Suape. Revista de Geografia (Recife) , v. 33, p. 117-140, 2016.

SANTOS, M. O. S. et al. Análise crítica do discurso da mídia impressa sobre a saúde e o ambiente no contexto da instalação da refinaria de petróleo em Suape, PE. Revista Eletrônica de Comunicação, Informação \& Inovação em Saúde, Rio de Janeiro, v. 6, n. 4, 2013. Disponível em: <http://www.reciis.cict.fiocruz.br/index.php/reciis/article/view/724/1393>. Acesso em: 21 mar. 2018.

SANTOS, M. O. S. Vulneração e injustiças ambientais na determinação social da saúde no território de Suape, Pernambuco/Brasil. Tese (Doutorado). Recife, Pós-Graduação em Saúde Pública. Instituto Aggeu Magalhães/Fiocruz, 2017.

SILVEIRA, M.; ARAÚJO NETO, M. D. de. Licenciamento ambiental de grandes empreendimentos: conexão possível entre saúde e meio ambiente. Ciência \& Saúde Coletiva, Rio de Janeiro, v. 19, n. 9, p. 3829-3838, 2014.

SCHÜTZ, G. E.; TAMBELliNI, A. T.; ASMUS, C. I. R. F.; MEYER, A.; CÂMARA, V. DE M. A agenda da sustentabilidade global e sua pauta oficial: uma análise crítica na perspectiva da Saúde Coletiva. Ciência \& Saúde Coletiva, v. 17, n. 6, p. 1407-1418, 2012.

TAMBELlinI, A. T. Sustentabilidade e sustenibilidade: um debate sobre a concepção de uma sociedade sustentável. Ciência \& Saúde Coletiva, v. 14, n. 6, p. 1977-1982, 2009. 